\title{
THE MAST CELL: ANOTHER MASTER IN ADIPOIMMUNOLOGY
}

\author{
Neşe Tunçel ${ }^{1}$, Stanislav Yanev ${ }^{2}$, Pepa Atanassova ${ }^{3}$, Jerzy Beltowski ${ }^{4}$, and Luigi Aloe ${ }^{5}$ \\ 'Department of Physiology, Medical Faculty, Osmangazi University, Eskişehir, Turkey, ${ }^{2}$ Department of Drug Toxicology, \\ Institute of Neurobiology, Bulgarian Academy of Sciences, Sofia, Bulgaria, ${ }^{3}$ Department of Anatomy and Histology, \\ Medical University, Plovdiv, Bulgaria, ${ }^{4}$ Department of Pathophysiology, Medical University, Lublin, Poland, and \\ ${ }^{5}$ Institute of Cell Biology and Neurobiology, National Research Council (CNR) Rome, Italy
}

\begin{abstract}
Recently, a large number of studies focus on (i) adipose tissue endocrine and paracrine function, and (ii) adipose-immune interactions herein referred to as adipoimmunology. In effect, a wide range of signaling proteins, dubbed adipokines, was identified as endocrine and paracrine secretory products of adipocytes and associated stromal vascular cells, including macrophages, lymphocytes and mast cells, the latter being less evaluated as compare to the formers. During obesity immune cells migrate into adipose tissue and inflame it by the secretion of a large amount of adipokines and thus trigger the development of so-called low grade inflammation-related diseases. Based on Steve Galli's concept of mast cell as master cells in many biological and pathological processes (New Engl J Meet 1993; 328:257265), here we highlight recent studies on the significance of adipose mast cells in the pathogenesis and therapy of cardiometabolic diseases (atherosclerosis, obesity, type 2 diabetes mellitus, metabolic syndrome) and breast cancer. Knowledge of the master work of these cells may provide a background for mast cell-targeted pharmacology for low grade inflammation-related diseases.
\end{abstract}

\section{Adipobiology 2015; 7: 15-19}

Key words: adipose tissue, adipokines, atherosclerosis, breast cancer, inflammation, mast cells, obesity

Received 8 December 2015, revised 18 December 2015, accepted 19 December 2015.

Correspondence to Dr Luigi Aloe, Institute of Cell Biology and Neurobiology, National Research Council (CNR) Rome, Italy.

E-mail: luigi.aloe@inmm.cnr.it

\section{Introduction}

In the last 20 years there is an increasing attention to the adipobiology of various diseases, one of the most exciting examples being the rapidly growing interest in understanding the adipose tissue secretion of multifunctional signaling proteins collectively designated adipokines (1-3). These molecules, via endocrine and paracrine way, are potent modulators of many biological processes including metabolism, inflammation, immunity, vascular contractility, and cell proliferation (4-17).

Here we review current data of adipose tissue paracrine signaling in the pathogenesis of low grade inflammation-related diseases, with special reference to the possible involvement of adipose mast cell's secretion of mastokines (mast cellderived adipokines). This may provide basis of mast cell-targeted adipopharmacology (18-22).

\section{Adipose tissue}

Adipose tissue is a cellular and extracellular matrix assembly composed of adipocytes, fibroblasts, immune cells and matrix components, also rich in sympathetic nerve fibers, blood vessels, and 
stem cells. In humans, particularly well developed is the white adipose tissue (WAT), a major metabolic and secretory organ. Human WAT is partitioned into two large depots (visceral and subcutaneous), and many small depots associated with various organs, including heart, blood vessels, major lymph nodes, pancreas, ovaries, bone marrow, eyes, prostate, and mammary glands. White adipose tissue may grow and shrink dramatically to meet the energetic needs of an organism. However, severe metabolic and inflammatory consequences can result from excessive WAT accumulation, featuring cardiometabolic diseases (CMD). Adipoimmunology of brown adipose tissue is out of the scope of present review.

Lean adipose tissue is populated with resident immune cells, which maintain tissue homeostasis through the secretion of adipokines that polarize adipose tissue macrophages $(\mathrm{M})$ in an anti-inflammatory phenotype, M2 state. Diet-induced obesity is associated with the loss of tissue homeostasis and development of type 1 inflammatory responses in WAT expressed by pro-inflammatory M1 phenotype (5, 9, 12-15).

\section{Adipokines: new players in inflammation and immunity}

Celsus's description ( $1^{\text {st }}$ century AD) of inflammation feature includes rubor et tumor cum calor et dolor. Inflammation is an essential biological response aiming at recovering from injury, wound healing being a paradigm of such a homeostatic phenomenon. However, what begins as a protective response, in excess becomes a damaging process, hence the inflammation is increasingly recognized as the underlying basis of a significant number of diseases. Recent genomic studies in human WAT revealed that a panel of inflammatory molecules was upregulated in obese compared to lean subjects $(2,3)$. These molecules are secretory products of adipocytes and associated stromal vascular cells, including macrophages, lymphocytes and mast cells. Of note, calorie restriction diet improved the anti-inflammatory profile of obese subjects via increase of anti-inflammatory and decrease of pro-inflammatory molecules. Further, weight loss resulted in decrease of adipose-associated immune cells and increased production of anti-inflammatory adpokines (7, 9-17). Such a sophisticated biology supports the hypothesis that adipokines may indeed be potent modulators of low grade inflammation associated with atherosclerosis, obesity, type 2 diabetes, metabolic syndrome, inflammatory bowel diseases, thyroidassociated (Graves') ophthalmopathy, breast cancer, and nonalcoholic fatty liver disease, to list some of many examples (1, 7, 9-18). Accordingly, the field of adipoimmunology of disease has attracted great attention, exemplified by the rapidly growing interest in understanding the adipose tissue protein secretion (4, $5,7,22,24-26)$.

\section{Mast cells}

Mast cells were first described in 1878 by Paul Ehrlich (18541915) in his doctoral thesis "Contribution to the Theory and Practice of Histological Staining" (4, 23 and references therein). Ehrlich observed that mast cells were commonly located in connective tissue near blood vessels and nerves, as well as in inflammatory and tumor lesions. Mast cells are phenotypically and functionally versatile effector cells that have been traditionally associated with the immunoglobulin E-mediated allergic response. However, recent studies implicate these cells in the regulation of inflammation, fibrosis, angiogenesis, hemostasis, cancerogenesis, and neuroimmune interactions $(4,7,8,18,23$ 28 ), which could associate with various low grade inflammatory diseases.

\section{Adipose mast cells}

Accumulating evidence demonstrates that the adipose mast cells could also be Galli's master cells (also see 8) in the secretion of multifunctional biomolecules herein referred to as mastokines (mast cells-derived cytokines/adipokines; Table 1). Their YinYang $(4,7)$, dual (8) regulatory activity should also be considered in adipoimmunology. At present, the study on adipobiology of mast cells is, however, limited as compared to that on other types of immune cells. PubMed search using the key words "adipose tissue and mast cells" up-regulates 162 articles in period between 1963 - December 2015, while "adipose tissue and macrophages" - 2539 articles, "adipose and lymphocytes" - 1171 articles.

Table 1. Selected list of adipose-derived mastokines

Leptin, IL-1, IL-4, TNF- $\alpha$, LIF, MCP-1 (CCL2), IL-8 (CXCL8), Eotaxin (CCL11)

RANTES (CCL5), FGF, TGF- $\beta$, NGF, CNTF, MCSF, VEGF, HGF Chymase, Tryptase, MMP, PAI-1, NO, VIP, Heparin, Histamine

Abbreviations: IL, interleukin; TNF-alpha, Tumor Necrosis Factor- $\alpha$; LIF, Leukemia Inhibitory Factor; MCP, Monocyte Chemoattractant Protein-1 (Cystein-Cystein modif Ligand); RANTES, Regulated on Activated Normal T-cell Expressed and Secreted; FGF, Fibroblast Growth Factor; TGF- $\beta$, Transforming Growth Factor-beta; NGF, Nerve Growth Factor; CNTF, Ciliary Neurotrophic Factor; MCSF, Macrophage Colony-Stimulating Factor; VAGF, Vascular Endothelium Growth Factor; HGF, Hepatocyte Growth Factor; MMP, Matrix Metalloproteinase; PAl, plasminogen activator inhibitor; NO, nitric oxide; VIP, vasointestinal peptide 


\section{Adipoimmunology of cardiometabolic disease}

The possibility that the endocrine secretory activity of large adipose depots may directly contribute to the altered blood levels of certain adipokines has recently gained considerable attention in studying obesity, type 2 diabetes and metabolic syndrome, examples of CMD $(1,7,18,24,25,29-31)$. Further, the paracrine secretory activity of periadventitial adipose tissue has also become a focus in the pathobiology of another part of CMD atherosclerosis and hypertension (18, 26-28).

A long standing paradigm holds that the vascular wall is composed of three concentric tissue coats (tunicae): intima, media, and adventitia. However, large- and medium-sized arteries, where usually atherosclerotic lesions develop, are consistently surrounded by periadventitial adipose tissue, which was recently designated tunica adiposa (in brief, adiposa like intima, media, and adventitia) (26 and references therein).

Neuro-immune-adipose interactions are illustrated in Figure 1 (also see Fig. 2 for neuro-immune link).

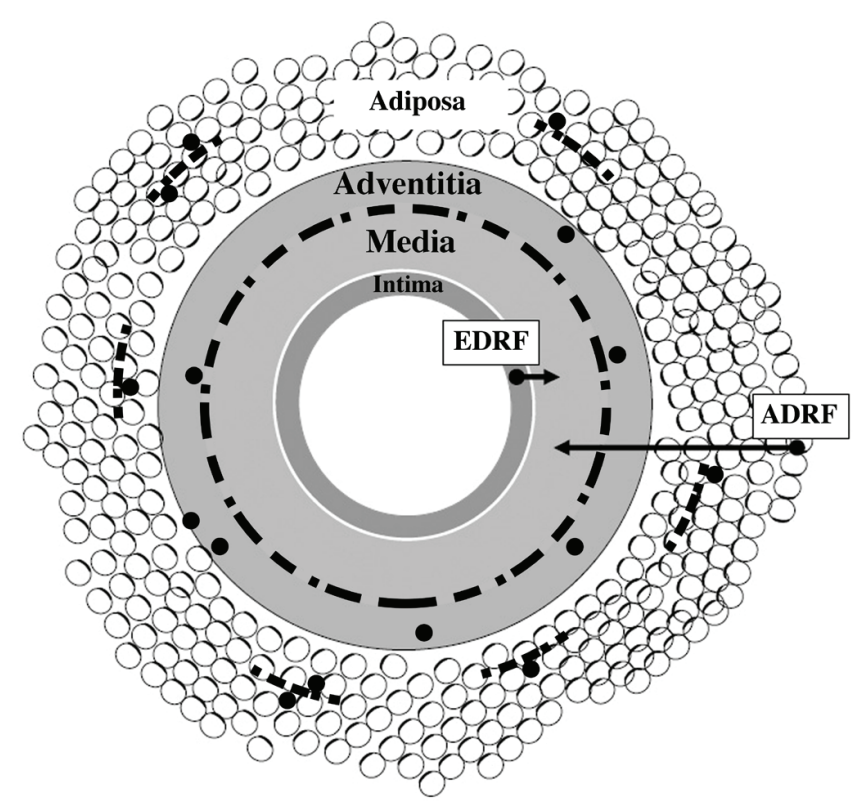

Figure 1. Schematic presentation of vascular wall composed of four tissue coats (tunicae): intima, media, adventitia, and adiposa. Arrows show that tunica media is a target for at least two vasorelaxing factors, endothelium-derived relaxing factor (EDRF) and adipocyte-derived relaxing factor (ADRF) respectively. Discontinuous black line positioned at the adventitia-media border illustrates perivascular nerves. Small-sized discontinuous black lines located in tunica adiposa indicate adipose nerves. Black granules (except those linked to arrows) illustrate immune cells - their association with nerves and adipocytes is also depicted. From (26).

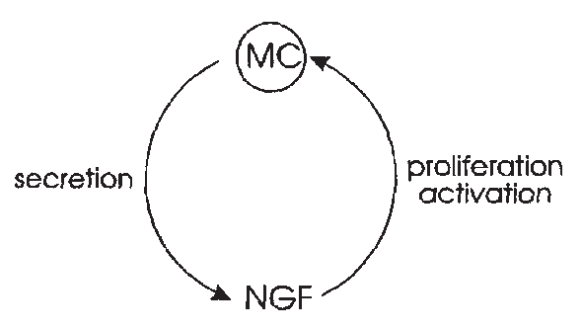

Figure 2. Mast cells (MC) are source of and target for nerve growth factor (NGF). From (4; also see 24, 25, 38).

\section{Adipoimmunology of breast cancer}

It is known that inflammation can promote tumorigenesis. There is compelling evidence indicating that both normal mammary gland development and breast cancer growth depend, in part, on microenvironment, of which adipose tissue is a key component. Adipose fibroblasts are thus important cellular component of breast cancer microenvironment. These cells, being bona fide steroidogenic cells, are one of the major extragonadal sources of estrogen secretion. Estrogen synthesis is mediated by the enzyme aromatase cytochrome P450 (CYP19) which converts androgens to estrogens. In breast cancer, one of the most aggressive human cancer, intratumoral proliferation of breast adipose fibroblasts is accompanied by an increased CYP19 expression by these cells, leading to proliferation of breast epithelial cells (7, 18 and references therein). Further, breast cancer commonly associates with a prominent immune, especially mast cell, response. Notably, both adipocytes and mast cells produce various adipokines known to upregulate aromatase expression. And, adipose- and mast cell-derived tryptase is a potent stimulator of fibroblast proliferation (4) as well as a potent angiogenic factor (see 7, 18).

A novel piece to the puzzle of breast cancer is that nerve growth factor (NGF), a neurotrophin known to be produced by mast cells $(24,25)$ as well as adipocytes (32), stimulates breast cancer cell proliferation (see 7, 18). Importantly, the antiestrogen drug tamoxifen inhibits NGF-mediated breast cancer cell proliferation through inhibition of the Trk-A receptor (see 7, 18). These data suggest a novel, NGF/mast cell-mediated mechanism in the action of an old drug, tamoxifen, in breast cancer pharmacotherapy. Together these findings open possibilities for an adipose NGF/mast cell-oriented therapy of breast cancer, and pressingly call for specific studies on both adipoimmunology and adipopharmacology of this neoplastic disorder. Noteworthy, an elegant study by Julio Celis and colleagues (33) provided the most extensive proteomic analysis of the mammary adipose secretome in high risk breast cancer patients. 


\section{Coda}

Adipose tissue is a major source of and target for inflammatory and fibroproliferative signals, mast cells being their master producer. It is worth concluding that adipocytes and mast cells both share several biological features in common: (i) they are bona fide secretory cell types, (ii) they secrete a wide range of same signaling molecules, and (iii) they are implicated in the pathobiology of various low grade inflammatory diseases. Further investigations aimed at pursuing cell-to-cell communications via adipose mast cell-derived extracellular vesicles (exosomes and ectosomes) (34-36) may bring a novel insight in adipoimmunology. And may prove whether adipose mast cells stand indeed as a master in this research field $(8,23-26,37,38)$.

\section{Conflict of interest}

The authors declare no conflict of interest.

\section{References}

1. Töre F, Tonchev AB, Fiore M, Tuncel N, Aloe L, Atanassova $\mathrm{P}$, et al. From adipose tissue protein secretion to adipopharmacology of disease. Immun Endoc Metab Agents Med Chem 2007; 7: 149-155. [DOI: 10.2174/187152207780363712]

2. Renes J, Rosenow A, Mariman E. Novel adipocyte features discovered by adipoproteomics. Adipobiology 2009; 1: 7-18. [DOI: http://dx.doi.org/10.14748/adipo.v1.245]

3. Renes J, Mariman E. Application of proteomics technology in adipocyte biology. Mol Biosyst 2013; 9: 1076-1091. [DOI: $10.1039 / \mathrm{c} 3 \mathrm{mb} 25596 \mathrm{~d}]$

4. Chaldakov GN, Ghenev PI, Valchanov KP, Tonchev AB, Pancheva R. Nerve-mast cell-nerve growth factor link: the mast cell as yin-yang modulator in inflammation and fibrosis. Biomed Rev 1995; 4: 1-6. [DOI: http://dx.doi. org/10.14748/bmr.v4.186]

5. Pond CM. Adipose tissue and the immune system. Prostaglandins Leukot Essent Fatty Acids 2005; 73: 17-30. [DOI: 10.1016/j.plefa.2005.04.005]

6. Tunçel N, Peker E, Sener ED, Tunçel M, Chaldakov GN, Tore F, et al. Cold exposure and adipose nitric oxide and mast cells: Influence on aorta contractility. Adipobiology 2009; 1: 67-75. [DOI: http://dx.doi.org/10.14748/adipo.v1.251]

7. Chaldakov GN, Tonchev A, Tuncel N, Atanassova P, Aloe L. Adipose tissue and mast cells. Adipokines as Yin-Yang modulators of inflammation. In: Fantuzzi G and Mazzone T, editors. Nutrition and Health: Adipose Tissue and Adipokines in Health and Disease. Humana Press Inc, Totowa, NJ, 2007; pp 151-158.
8. Galli SJ, Grimbaldeston M, Tsai M. Immunomodulatory mast cells: negative, as well as positive, regulators of immunity. Nat Rev Immunol 2008; 8: 478-486. [DOI: nri2327 [pii];10.1038/nri2327]

9. Bouloumie A, Casteilla L, Lafontan M. Adipose tissue lymphocytes and macrophages in obesity and insulin resistance: makers or markers, and which comes first? Arterioscler Thromb Vasc Biol 2008; 28: 1211-1213. [DOI: 10.1161/ ATVBAHA.108.168229]

10. Sun S, Ji Y, Kersten S, Qi L. Mechanisms of inflammatory responses in obese adipose tissue. Annu Rev Nutr 2012; 32: 261-286. [DOI: 10.1146/annurev-nutr-071811-150623]

11. Akasheh RT, Pang J, Fantuzzi G. New pathways to control inflammatory responses in adipose tissue. Curr Opin Pharmacol 2013; 13: 613-617. [DOI: 10.1016/j. coph.2013.04.008]

12. O'Rourke RW, Gaston GD, Meyer KA, White AE, Marks DL. Adipose tissue NK cells manifest an activated phenotype in human obesity. Metabolism - Clinical and Experimental 2013; 62: 1557-1561. [DOI: 10.1016/j.metabol.2013.07.011]

13. Jin YH, Yoon JP, Mira H, Jae BK. Crosstalk between adipocytes and immune cells in adipose tissue inflammation and metabolic dysregulation in obesity. Mol Cells 2014; 37: 365371. [DOI: 10.14348/molcells.2014.0074]

14. Bouckenooghe T, Sisino G, Aurientis S, Chinetti-Gbaguidi G, Kerr-Conte J, Staels B, et al. Adipose tissue macrophages (ATM) of obese patients are releasing increased levels of prolactin during an inflammatory challenge: A role for prolactin in diabesity? Bioch Biophys Acta - Mol Basis Dis 2014; 1842: 584-593.

15. Altintas MM, Azad A, Nayer B, Contreras G, Zaias J, Faul $\mathrm{C}$, et al. Mast cells, macrophages, and crown-like structures distinguish subcutaneous from visceral fat in mice. J Lipid Res 2010; 52: 480-488. [DOI: 10.1194/jlr.M011338 ]

16. Lindsberg PJ, Strbian D, Karjalainen-Lindsberg ML. Mast cells as early responders in the regulation of acute bloodbrain barrier changes after cerebral ischemia and hemorrhage. J Cereb Blood Flow Metab 2010; 30:689-702. [DOI: 10.1038/jcbfm.2009.282]

17. Ribatti D. The crucial role of mast cells in blood-brain barrier alterations. Exp Cell Res 2015; 338:119-125. [DOI: 10.1016/j.yexcr.2015.05.013]

18. Chaldakov GN, Stankulov IS, Hristova MG, Ghenev PI. Adipobiology of disease: adipokines and adipokine-targeted pharmacology. Curr Pharm Des 2003; 9: 1023-1031. [DOI: 10.2174/1381612033455152] 
19. Liu J, Divoux A, Sun J, Zhang J, Clement K, Glickman JN, et al. Genetic deficiency and pharmacological stabilization of mast cells reduce diet-induced obesity and diabetes in mice. Nat Med 2009; 15: 940-945. [DOI: 10.1038/nm.1994]

20. Wang J, Shi GP. Mast cell stabilization: novel medication for obesity and diabetes. Diab Metab Res Rev 2011; 27: 919-924. [DOI: 10.1002/dmrr.1272]

21. Altintas MM, Nayer B, Walford EC, Johnson KB, Gaidosh $\mathrm{G}$, Reiser J, et al. Leptin deficiency-induced obesity affects the density of mast cells in abdominal fat depots and lymph nodes in mice. Lipids Health Dis 2012; 11: 21. [DOI: 10.1186/1476-511X-11-21]

22. Spencer M, Yang L, Adu A, Finlin BS, Zhu B, Shipp LR, et al. Pioglitazone treatment reduces adipose tissue inflammation through reduction of mast cell and macrophage number and by improving vascularity. PLoS.One. 2014; 9: e102190. [DOI: 10.1371/journal.pone.0102190]

23. Vyas H, Krishnaswamy G. Paul Ehrlich's "Mastzellen”- from aniline dyes to DNA chip arrays: a historical review of developments in mast cell research. Methods Mol Biol 2006; 315: 3-11. [DOI: 10.1385/1-59259-967-2:003]

24. Aloe L, Levi-Montalcini R. Mast cells increase in tissues of neonatal rats injected with the nerve growth factor. Brain Res 1977; 133: 358-366. [DOI: 0006-8993(77)90772-7]

25. Leon A, Buriani A, Toso RD, Fabbi M, Romanello S, Aloe L. Mast cells synthesize, store, and release nerve growth factor. Proc Natl Acad Sci USA 1994; 91: 3739-3743.

26. Chaldakov GN, Fiore M, Ghenev PI, Beltowski J, Rancic G, Tuncel N, et al. Triactome: neuro-immune-adipose interactions. Implication in vascular biology. Front Immunol 2014; 5: 130. [DOI: 10.3389/fimmu.2014.00130]

27. Chaldakov GN, Fiore M, Stankulov IS, Hristova $M$, Antonelli A, Manni L, et al. NGF, BDNF, leptin, and mast cells in human coronary atherosclerosis and metabolic syndrome. Arch Physiol Biochem 2001; 109: 357-360. [DOI: 10.1076/apab.109.4.357.4249]

28. Chaldakov GN, Stankulov IS, Fiore M, Ghenev PI, Aloe L. Nerve growth factor levels and mast cell distribution in human coronary atherosclerosis. Atherosclerosis 2001; 159: 57 66. [DOI: S0021-9150(01)00488-9]

29. Shi MA, Shi GP. Different roles of mast cells in obesity and diabetes: lessons from experimental animals and humans. Front Immunol 2012; 3: [DOI: 10.3389/fimmu.2012.00007]

30. Divoux A, Moutel S, Poitou C, Lacasa D, Veyrie N, Aissat A, et al. Mast cells in human adipose tissue: link with morbid obesity, inflammatory status, and diabetes. J Clin Endocrinol Metab 2012; 97: E1677-E1685. [DOI: 10.1210/jc.2012-1532]

31. Zhang J, Shi GP. Mast cells and metabolic syndrome. Biochem Biophys Acta - Mol Basis Dis 2012; 1822: 14-20. [DOI: 10.1016/j.bbadis.2010.12.0121]

32. Sornelli F, Fiore M, Chaldakov GN, Aloe L. Adipose tissuederived nerve growth factor and brain-derived neurotrophic factor: results from experimental stress and diabetes. Gen Physiol Biophys 2009; 28: 179-183. [DOI: PMID: 19893098]

33. Celis JE, Moreira JM, Cabezon T, Gromov P, Friis E, Rank $\mathrm{F}$, et al. Identification of extracellular and intracellular signaling components of the mammary adipose tissue and its interstitial fluid in high risk breast cancer patients: toward dissecting the molecular circuitry of epithelial-adipocyte stromal cell interactions. Mol Cell Proteomics 2005; 4: 492522. [DOI: 10.1074/mcp.M500030-MCP200]

34. Skokos D, Le Panse S, Villa I, Rousselle J-C, Peronet R, David $\mathrm{B}$, et al. Mast cell-dependent B and T lymphocyte activation is mediated by the secretion of immunologically active exosomes. J Immunol 2001; 166:868-876. [DOI: 10.4049/jimmunol.166.2.868]

35. Ogawa R, Tanaka C, Sato M, Nagasaki H, Sugimura K, Okamura $\mathrm{K}$, et al. Adipocyte-derived microvesicles contain RNA that is transported into macrophages and might be secreted into blood circulation. Biochem Biophys Res Commun 2010; 398: 723-729. [DOI:10.1016/j.bbrc.2010.07.008]

36. Shefler I, Solomon P, Alon YH, Hershko AY, Mekori AY. Mast cells as sources and targets of membrane vesicles. Curr Pharm Des 2011; 17: 3797-3804. [http://dx.doi. org/10.2174/138161211798357836]

37. Tunçel N. Mast cells, vasoactive intestinal peptide (VIP), and the hemorrhagic shock: a possible relationship? Biomed Rev 1993; 2: 37-46. [DOI: http://dx.doi.org/10.14748/bmr. v2.210]

38. Aloe L, Tuveri MA, Angelucci F. Nerve growth factor, mast cells and arthritis. Biomed Rev 1995; 4: 7-14. [DOI: http:// dx.doi.org/10.14748/bmr.v4.187] 